\title{
Respiratory involvement in juvenile dermatomyositis
}

\section{Fabi*1, M Le Bourgeois², C Bodemer ${ }^{3}$, V Beguin ${ }^{2}$, AM Prieur ${ }^{4}$, P Quartier ${ }^{4}$ and $\mathrm{J}$ de $\mathrm{Blic}^{2}$}

\author{
Address: ${ }^{1}$ Pediatric Unit, Ospedale S.Orsola-Malpighi, Bologna, Italy, ${ }^{2}$ Service de Pneumologie et Allergologie Pédiatriques, Hôpital Necker- \\ Enfants Malades, Paris, France, ${ }^{3}$ Service de Dermatologie Pédiatrique, Hôpital Necker- Enfants Malades, Paris, France and ${ }^{4}$ Service de \\ Rheumatologie Pédiatriques, Hôpital Necker- Enfants Malades, Paris, France \\ * Corresponding author
}

from $15^{\text {th }}$ Paediatric Rheumatology European Society (PreS) Congress

London, UK. 14-17 September 2008

Published: 15 September 2008

Pediatric Rheumatology 2008, 6(Suppl I):P219 doi:10.1186/1546-0096-6-SI-P219

This abstract is available from: http://www.ped-rheum.com/content/6/SI/P2I9

(c) 2008 Fabi et al; licensee BioMed Central Ltd.

\section{Background}

Juvenile dermatomyositis (JDM) is a rare chronic idiopathic inflammatory disorder primarily affecting the striated muscle and the skin. Pulmonary involvement is a common complication and cause of morbidity and mortality, but few data are available concerning pulmonary function impairment in childhood.

The aim of this prospective study was to assess pulmonary function impairment in JDM.

\section{Materials and methods}

16 patients (9 girls) with diagnosis of JDM (age 3-16,2 yrs) performed pulmonary function tests (PFT). 14 were receiving treatment; all had muscular testing. 13 had weakness as major symptom. Respiratory symptoms: dry cough in 2/16; reduced exercise tolerance: $3 / 16$. Chest $x^{-}$ ray: normal in 13/13. Echocardiogram and ECG: normal in all. 9/16 had positive ANA-Ab; antiJO1 Ab negative in all.

\section{Results}

7/15 pt (46\%): restrictive syndrome measured on TLC and VC; 9/16 (56\%): reduced FRC; 9/13 pt: reduced RV. DLCO: impaired in 2 with restrictive pattern. No patient had bronchial obstruction. We didn't find a relation between PFT and steroid treatment/impregnation, nor with relapses, nor with muscle enzymes nor with ANA/ FAN. Muscular testing didn't always correlate with respiratory impairment.

\section{Conclusion}

Lung involvement is frequent in JDM and is better detected by PFT than by chest x-ray or symptoms. The most frequent respiratory pattern is restrictive syndrome secondary to respiratory muscular deficit and evidenced by a reduction of lung volumes with normal DLCO and chest x-ray. We couldn't detect any risk factor predicting a major lung involvement, but the longer is the follow-up, the more frequent a functional impairment is present. 